\title{
High Tunnels Can Promote Growth, Yield, and Fruit Quality of Organic Bitter Melons (Momordica charantia) in Regions with Cool and Short Growing Seasons
}

Yun Kong, David Llewellyn, Katherine Schiestel, Martha Gay Scroggin David Lubitz, Mary Ruth McDonald, Rene Van Acker, Ralph C. Martin, and Youbin Zheng ${ }^{1}$

Ontario Agricultural College, University of Guelph, 50 Stone Road East, Guelph, Ontario N1G 2W1, Canada

\section{Evan Elford \\ Ontario Ministry of Agriculture, Food and Rural Affairs, 1 Stone Road West, Guelph, Ontario N1G 4Y2, Canada}

Additional index words. anti-insect netting, pest, disease incidence

\begin{abstract}
There is a potentially large market for locally produced organic bitter melons (Momordica charantia L.) in Canada, but it is a great challenge to grow this warmseason crop in open fields (OFs) due to the cool and short growing season. To test the feasibility of using high tunnels (HTs) for organic production of bitter melons in southern Ontario, plant growth, fruit yield and quality, and pest and disease incidence were compared among three production systems: OF, HT, and high tunnel with antiinsect netting (HTN) at Guelph in 2015. The highest marketable fruit yield was achieved in HTN $\left(\approx 36 \mathrm{t} \cdot \mathrm{ha}^{-1}\right)$, followed by HT $\left(\approx 29 \mathrm{t} \cdot \mathrm{ha}^{-1}\right)$, with the lowest yield obtained in OF $\left(\approx 3 \mathrm{t} \cdot \mathrm{ha}^{-1}\right)$. Compared with OF, there were several other benefits for bitter melon production in HT and HTN: increased plant growth, advanced harvest timing, reduced pest numbers and disease incidence, and improved fruit quality traits such as increased individual fruit weight and size, and reduced postharvest water loss. In addition to higher yield, HTN had fewer insect pests and disease incidence compared with HT. The results suggest that HTs can be used for organic production of bitter melon in southern Ontario and regions with similar climates. Also, the addition of anti-insect netting to HTs is beneficial to production if combined with an effective pollination strategy.
\end{abstract}

Bitter melon (Momordica charantia), also known as bitter gourd, karela, or balsam pear (Palada and Chang, 2003), is a popular vegetable for many culture groups in Canadian urban centers, such as the Greater Toronto Area. Consumption of bitter melon has also been shown to be beneficial for the management of some symptoms of type II diabetes (Abascal and Yarnell, 2005). It is estimated that there is a CAD\$12.4 million/year market

Received for publication 5 Aug. 2016. Accepted for publication 27 Oct. 2016.

This project was supported by Agriculture and Agri-Food Canada's Organic Cluster Research Program and managed by Organic Agriculture Centre of Canada. The Ontario Ministry of Agriculture, Food and Rural Affairs supported on-site climate characterization through the University of Guelph Partnership program.

We thank Nora Alsafi, Patrick Kelly, and Amy Kong for their excellent technical support. We also thank the anonymous reviewers for their very useful and helpful suggestions on the revision of this manuscript.

${ }^{1}$ Corresponding author. E-mail: yzheng@uoguelph.ca. for bitter melons in just a few of the largest Canadian metropolitan centers, and a potential countrywide market of CAD\$37-66 million/ year (Zheng, 2010).

Currently, the majority of bitter melons sold in Canada are imported from other countries such as Honduras (Zheng, 2010). However, for the imported bitter melons, the lost freshness due to a short postharvest life of the fruits (Palada and Chang, 2003) negatively affects their price, and Canadian consumers also worry about food safety of imported bitter melons. Moreover, there is hardly any organic bitter melon in Canadian market. Although there is a demand for local, organically produced bitter melon, the supply of such products is currently limited by Canada's cold climate (Zheng, 2010). Bitter melons, which are native to southern China and eastern India, grow well in tropical and subtropical climates (Behera et al., 2010). In Canada, OF production of warm-season crops such as bitter melons is difficult unless some means are employed to improve the growing environment (Waterer, 2003).
HTs, as low-cost protective structures, can create a warmer microclimate for plants and have been used worldwide to promote earlier crop production, higher yields per unit area, and better-quality products compared with OF production (Lamont, 2009; Ogden and Van Iersel, 2009). However, since HTs are unheated and passively ventilated structures, the actual benefits of HT production for different crop species are determined by local environmental conditions (Carey et al., 2009). There is limited information on HT production under Canadian climatic conditions, especially in Ontario. In Saskatchewan, it has been reported that crops of muskmelon, pepper, and tomato in HTs matured 1 to 2 weeks earlier and produced substantially greater fruit yields before frost than those in low tunnels (Waterer, 2003). However, no information is available on whether HTs can be used for bitter melon production in regions with similarly short growing seasons, such as Ontario.

For organic production, the use of antiinsect netting on the vents and doors of HTs is often recommended, since it can provide a nonchemical way to effectively exclude many insect pests (Teitel, 2001). For bitter melon production in tropical and subtropical regions, the most common insect pests are fruit flies, beetles, thrips, aphids, and mites (Palada and Chang, 2003). These pests have been found in other cucurbit crops in southern Ontario. To exclude these pests, the maximum mesh size of anti-insect netting needs to be small; up to around $200 \mu \mathrm{m}$ (Bethke and Paine, 1991). However, fine mesh size also impedes air flow through the netting and may thus increase temperature inside HTs (Fatnassi et al., 2006). During summer in southern Ontario, solar radiation intensity often exceeds most crops' requirements (Llewellyn et al., 2013). Excessive solar radiation can increase air temperatures beyond the optimum for growing crops in protected agricultural structures that use passive ventilation, including HTs (Zhang, 2001). It is therefore important to test the impact anti-insect netting has on HT temperature and organic bitter melon production, including growth and harvest metrics as well as incidence of insects and diseases.

The objectives of this study were to explore the feasibility of organic production of bitter melons in HTs in southern Ontario, and to determine the effects of anti-insect netting on HT production of organic bitter melon.

\section{Materials and Methods}

Experimental site and design. The trial was conducted at the Guelph Center for Urban Organic Farming, Guelph, Ontario, Canada (lat. $43^{\circ} 33^{\prime} \mathrm{N}$, long. $80^{\circ} 15^{\prime} \mathrm{W}$ ) during the 2015 growing season. This farm has been certified organic by Ecocert Canada since 2009 . The soil is a clay loam with limestone bedrock, $3.5 \%$ to $6 \%$ organic matter, and $\mathrm{pH}$ 7.4. Cover crops of buckwheat (Fagopyrum esculentum) and sorghum (Sorghum bicolor), lightly underseeded with 
red clover (Trifolium pratense), were used to maintain soil stability and structure and reduce weed incidence, in the years before this trial. There was no recent history of Momordica production at this site.

Six freestanding, NE-SW oriented, quonset-style HTs $(10.8 \mathrm{~m}$ long $\times 7.2 \mathrm{~m}$ wide $\times 3.8 \mathrm{~m}$ high; DeCloet Greenhouse Mfg. Ltd., Delhi, Ontario, Canada) were constructed on-site in the fall of 2014. The side vents and door openings of three of the tunnels were installed with Econet $\mathrm{T}$ antiinsect screens (Gintec Shade Technologies Inc., Windham Center, Ontario, Canada), which has $0.15 \mathrm{~mm} \times 0.35 \mathrm{~mm}$ hole size, $0.5 \mathrm{~mm}$ thread diameter, and $85 \%$ initial light transmission. These tunnels represented the HTN treatment. The other three tunnels, without anti-insect netting, were used as the HT treatment. Three equivalent-sized field plots $(10.8 \mathrm{~m} \times 7.2 \mathrm{~m})$ were established as controls (OF treatment). The nine rectangular plots were arranged as a $3 \times 3$ randomized block design with 3-m buffer zones between adjacent plots (Fig. 1).

The tunnels were covered with a single layer of $0.15-\mathrm{mm}$ polyethylene film with 90\% initial light (photosynthetically active radiation) transmission (Suncover Clear CA; Ginegar Plastic Products Ltd., Kibbutz Ginegar, Israel). Doors built into the end walls were wide enough to allow the passage of a rototiller. The side walls were manually rolled up or down to adjust interior air temperature based on weather conditions and crop requirements.

The soil in all nine plots was cultivated by a rototiller before transplanting, and then $0.8 \mathrm{~m} \times 0.25 \mathrm{~m} \times 10.3 \mathrm{~m}$ raised beds, spaced $0.4 \mathrm{~m}$ apart, were prepared. One drip irrigation line (Garden Drip Tape, GO151000; Dubois Agrinovation Inc., St-Rémi, Québec, Canada) was installed down the middle of each raised bed.

Plant materials and management. Bitter melon (Momordica charantia, 'Canton Green F1'; AgroHaitai Ltd., Lynden, Ontario, Canada) seedlings were propagated using a peatperlite mix (Pro-Mix MP MYCORRHIZAE ORGANIK; Premier Tech Horticulture Ltd., Rivière-du-Loup, Québec, Canada). Since the killing frost can occur until the end of May in this region, the transplant date for OF plots was scheduled for early June. Taken into account that spring production of warmseason crops can start around 1 month earlier in HTs vs. OFs in Pennsylvania (Orzolek, 2013), the transplanting date for HT and HTN plots was scheduled for early May. The specific sowing and transplanting dates are listed in Table 1. The seedlings had 13-14 true leaves and were $68-73 \mathrm{~cm}$ tall at the time of transplanting.

In each bed, the seedlings were planted alternately, in double rows spaced $30 \mathrm{~cm}$ apart, with an in-row spacing of $140 \mathrm{~cm}$. This resulted in a planting density of $\approx 17,000$ plants/ha, which is within the optimal density range recommended for standard field production of bitter melon (Behera et al., 2010; Wang, 2003). After transplanting into
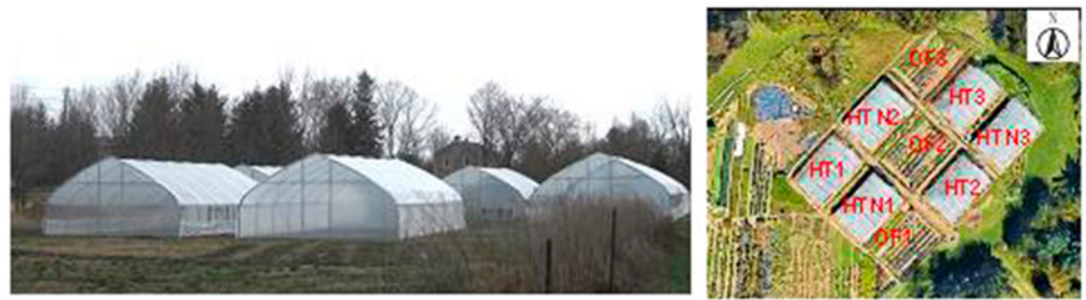

Fig. 1. Side (left) and aerial (right) views of HT $(10.8 \mathrm{~m} \times 7.2 \mathrm{~m} \times 3.8 \mathrm{~m})$ and OF plots for the $2015 \mathrm{bitter}$ melon production trial at the Guelph Center for Urban Organic Farming, Guelph, Ontario, Canada. OF $=$ open field; $\mathrm{HT}=$ high tunnel; $\mathrm{HTN}=$ high tunnel with anti-insect netting.

Table 1. Key time points for bitter melon production in different cultivation systems in southern Ontario during the trial in 2015 .

\begin{tabular}{lcccc}
\hline Treatment & Sowing date & Transplanting date & Fruit harvesting period & Killing frost date $\left(<-3{ }^{\circ} \mathrm{C}\right)$ \\
\hline OF & Apr. 20 & June 3 & Aug. 5-Oct. 14 & Oct. 16 \\
HT & Mar. 21 & May 7 & June 24-Oct. 14 & Oct. 16 \\
HTN & Mar. 21 & May 7 & June 24-Oct. 14 & Oct. 16 \\
\hline
\end{tabular}

$\mathrm{OF}=$ open field; $\mathrm{HT}=$ high tunnel; HTN $=$ high tunnel with anti-insect netting.

the HTs, plastic mulching materials $(36 \times$ $4000 \times 9$ BLACK TAFFETA EMB; Dubois Agrinovation Inc.) were used temporarily to protect the plants from killing frost on several nights in late May. Plants were trained to grow up a vertical string by one leader vine, and side branches were removed except where female flowers appeared on the five nodes proximal to the leader vine. The side branches which bore female flowers were pinched off above the distal flower position. Hand pollination of the opened female flowers was carried out (daily) in all the plots using male flowers from nearby plants. Once the fruits reached eating maturity (Morgan and Midmore, 2002; Wang, 2003), they were harvested once or twice weekly for the rest of the season, until the plants were killed by frost in the fall.

Basal fertilizers were incorporated into the soil of each plot, before planting, at a rate of 300 and $500 \mathrm{~kg} \cdot \mathrm{ha}^{-1}$ of General Purpose 4-3-9 and Blood Meal 12-0-0, respectively (BioFert Manufacturing Inc., Abbotsford, British Columbia, Canada) based on the recommendations from the fertilizer provider. Starting 8 weeks after transplanting, General Purpose 2.5-2-5 liquid fertilizer (BioFert Manufacturing Inc.) was applied to the root zones at a rate of $182 \mathrm{~L} \cdot \mathrm{ha}^{-1}$ every 10-14 d. After transplanting, water was applied to root-zone soil at up to $1.8 \mathrm{~L} \cdot \mathrm{m}^{-2}$, weekly, varying with precipitation and crop needs. Straw mulch was applied to each bed to suppress weeds $40 \mathrm{~d}$ after transplanting. Crops were inspected weekly for insect and disease problems. All the cultural practices and materials used met the requirements of the Organic Products Regulations (Canadian Food Inspection Agency, 2009) and Organic Production Systems Standards (Standards Council of Canada, 2006).

Evaluation of plant growth and development. After transplanting, 14-18 plants were randomly sampled, weekly, from each plot to measure the length and number of nodes on the leader vine. The flowering dates of the first female flowers on both the leader vines and side branches of each plant were recorded. These data were used to calculate the flower initiation time (flowering date - transplanting date) and fruit growth days (harvesting date flowering date) for the first fruits to appear on the main stem and side branches, respectively. At the end of production period, six plants were randomly selected from each plot to measure the leader vine diameter at the second internode, as well as the length and node number of the leader vine. Following this, each selected plant was cut above the first node of the leader vine, and dried in an oven at $65^{\circ} \mathrm{C}$ for $10 \mathrm{~d}$ to determine the dry weight (DW) of the aboveground vegetative biomass.

Fruit yield and quality investigation. At each harvest, fruits from the same plants that were sampled for weekly growth measurements were counted, weighed, and measured for their length and diameter. Harvested fruits were graded as marketable or unmarketable, with the latter being scarred or deformed fruits. The cumulative number and weight of marketable fruits per plant were determined for each week during the harvest period. At the end of harvest, percentages of scarred and deformed fruits, within the total yields, were calculated, respectively.

During the weeks of peak harvest, a total of 48 marketable fruits were randomly sampled from each treatment. Half of these fruits were used to measure flesh thickness and the other half were used to evaluate postharvest water loss. For the former measurement, each fruit was cut into two halves from the middle line along the long axis, and the flesh thickness in the middle part of the fruit was measured using a digital Vernier caliper after taking out all the seeds in the fruit. For the latter measurement, after recording the initial fresh weights $\left(\mathrm{FW}_{i}\right)$, the sampled fruits were kept in paper bags at $23{ }^{\circ} \mathrm{C}$ for $4 \mathrm{~d}$ to determine the final fresh weights $\left(\mathrm{FW}_{f}\right)$, and then dried at $65^{\circ} \mathrm{C}$ to determine the DW. The postharvest water loss [Eq. (1)], dry matter 
content [Eq. (2)], and water content [Eq. (3)] of the fruits were calculated as follows:

Postharvest water loss (\%)

$$
=\frac{\mathrm{FW}_{i}-\mathrm{FW}_{f}}{\mathrm{FW}_{i}} \times 100
$$

$$
\text { Dry matter content }(\%)=\frac{\mathrm{DW}}{\mathrm{FW}_{i}} \times 100
$$

Water content $\left(\mathrm{g} \cdot \mathrm{g}^{-1}\right)=\frac{\mathrm{FW}_{i}-\mathrm{DW}}{\mathrm{DW}}$

Insect and disease evaluations. Yellow and blue sticky traps $(7.5 \mathrm{~cm} \times 12 \mathrm{~cm}$; Canadian Hydrogardens Ltd., Ancaster, Ontario, Canada) were hung amid the plant canopy, at a height of $150 \mathrm{~cm}$ in each plot, to trap flying insects. All insects on each trap were counted weekly and used to determine cumulative totals at the end of crop production. Disease incidence was checked weekly, and the numbers of infected and dead plants due to disease were recorded in each plot.

Weather parameter recording. Weather parameters were measured continuously at 1 min intervals at the geometric center of one plot of each treatment (Fig. 1; OF2, HT2, and HTN2). Air temperature was measured 100 $\mathrm{cm}$ aboveground using RMY Young 81000 sonic anemometers (RM Young, Traverse City, MI), and recorded using Campbell Scientific CR1000 data loggers (Campbell Scientific, Logan, UT). Soil temperature was measured at 11.4-cm depth using PT916 thermistors. Solar radiation was measured at $150 \mathrm{~cm}$ aboveground using SRS-100 pyranometers (Pace Scientific Inc., Mooresville, NC). Soil temperature and radiation data were recorded using XR5-SE data loggers (Pace Scientific Inc.). The calibration of all sensors was verified experimentally before deployment. These environmental data were used for the calculation of daily average air and soil temperatures, and daily light integrals (DLIs). Monthly precipitation data were sourced from Environment Canada. Figure 2 shows average monthly weather situations for the site calculated from these data.

Statistical analysis. Data were subjected to analysis of variance using the Data Processing System Software (DPS, version 7.05; Refine Information Tech. Co., Hangzhou, China) and were presented as means \pm SE. Separation of means was performed using Duncan's new multiple range test at the $P \leq$ 0.05 level. Logistic [Eq. (4)] or Gompertz [Eq. (5)] formulae were used to fit the curves of variation of cumulative marketable yield with weeks of harvesting.

$$
\begin{gathered}
Y=\frac{a}{1+e^{b-k X}} \\
Y=a e^{-b e^{-k X}}
\end{gathered}
$$

where $Y=$ cumulative marketable yield (kg/plant, or number/plant); $X=$ weeks
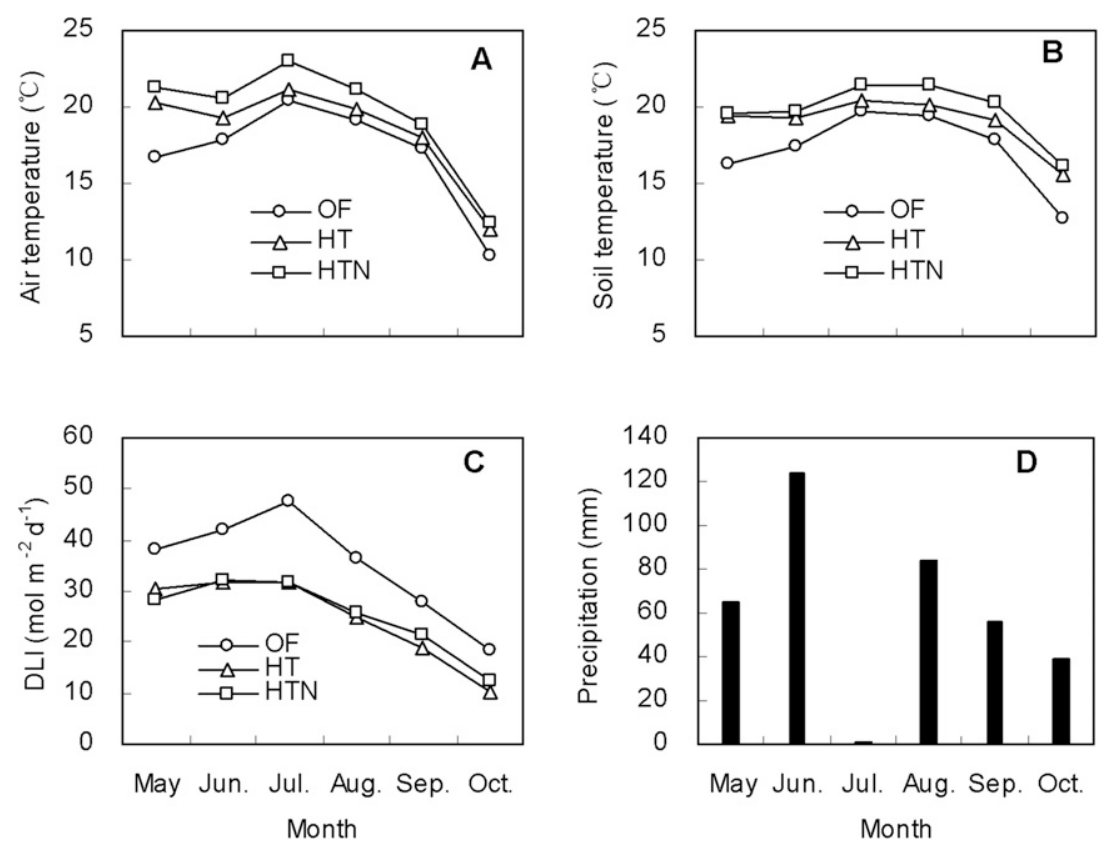

Fig. 2. Monthly variation of (A) daily mean air temperature, $(\mathbf{B})$ soil temperature, $(\mathbf{C})$ daily light integrals (DLI) in different cultivation systems, and (D) monthly precipitation in Guelph, Ontario, Canada in 2015. $\mathrm{OF}=$ open field; HT = high tunnel; HTN = high tunnel with anti-insect netting.

since the beginning of harvesting (week); $a$, $b, k$ are parameters to be fitted; and $e=$ exponential $=2.71828$. To describe the features of the curves, three parameters were calculated as follows: inflexion time point $=$ $\ln (b) / k$; maximum weekly yield increment $=$ $a \times k / 4$ (logistic), or $a \times k / 2.7$ (Gompertz); and upper limit of marketable yield $=a$ (Ma et al., 2013). Correlation analysis was used to determine the relationship between marketable fruit yield or fruit quality traits vs. growth of the bitter melon plants.

\section{Results}

Environmental parameters. Weather conditions during the whole 2015 growing season were generally similar to the long-term average except that rainfall was distributed unevenly between June and July (Fig. 2). Daily mean air and soil temperatures were the highest in HTN, followed by HT, and the lowest in OF. For example, during May the daily mean air temperatures were $21.3,20.2$, and $16.7^{\circ} \mathrm{C}$ and the daily mean soil temperatures were $19.5,19.4$, and $16.3{ }^{\circ} \mathrm{C}$ in the HTN, HT, and OF treatments, respectively (Fig. 2A and B). During May, daily mean soil temperatures were consistently above $15^{\circ} \mathrm{C}$ in HTN and HT, but were below $15{ }^{\circ} \mathrm{C}$ for $21 \mathrm{~d}$ in OF (data not shown). However, due to the shading effects of plastic coverings, the DLI was lower by around $20 \%$ in HTN and HT vs. OF (Fig. 2C).

Plant growth and development. Due to the higher temperatures (especially soil temperatures) (Fig. 2), the bitter melon plants were transplanted $27 \mathrm{~d}$ earlier into HT and HTN vs. OF (Table 1). Plant leader vines in HT and HTN showed higher growth rates than those in OF, regardless of time, but there were no significant differences in the rate of vine growth between HT and HTN (Fig. 3).

The first female flowers opened in late June in HT and HTN plots and in mid August in OF plots. The first female flowers appeared 15-20 d faster, relative to the transplant date, in HT and HTN vs. in OF, with no significant difference between HT and HTN (Fig. 4A). Furthermore, the time between flowering and harvesting of the first fruits was 2 to $4(10 \%$ to $20 \%) \mathrm{d}$ shorter in HT and HTN vs. OF (Fig. 4B).

At the end of the production season, the plants in HT and HTN had longer and thicker leader vines, with more nodes, and greater aboveground DW (not including fruits) than those in OF, but there were no significant differences between HT and HTN (Table 2).

Fruit yield and quality. Fruit harvest started 6 weeks earlier in HT and HTN than in OF (Fig. 5), though it ended on the same date in all treatments (Table 1) due to a killing frost on a night of mid October, when the air temperature dropped below $-3{ }^{\circ} \mathrm{C}$. By the end of the production season, both the total weight and number of marketable fruits harvested from each plant were greatest in HTN, followed closely by HT, and were lowest in OF (Fig. 5). The weekly variation of cumulative yield was characterized using either logistic or Gompertz formulae (Table 3). The maximum weekly yield increments in HT and HTN (collectively, HT plots) were 4-5 times (by fruit weight) and 2-3 times (by fruit number) of those in OF. The weekly yield increment began to slow about 2 weeks in OF and 7.5 weeks in HT and HTN after the start of harvest. By the end of the production season, 

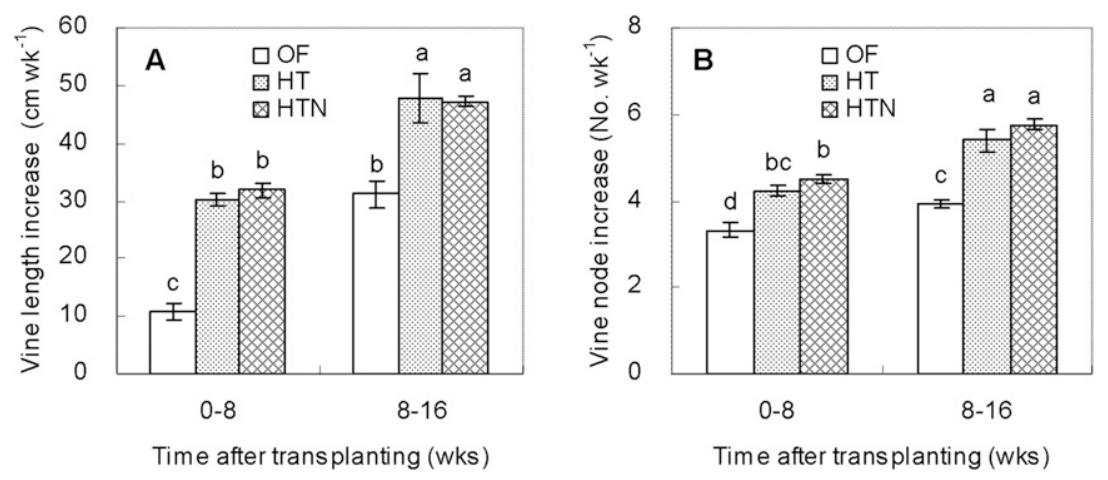

Fig. 3. Growth rate of the leader vine at different growth stages in bitter melon plants under different cultivation systems. Data are means $\pm \mathrm{SE}$. Bars bearing the same letter are not significantly different at $P$ $\leq 0.05$ according to Duncan's new multiple range test. $\mathrm{OF}=$ open field; $\mathrm{HT}=$ high tunnel; $\mathrm{HTN}=$ high tunnel with anti-insect netting.
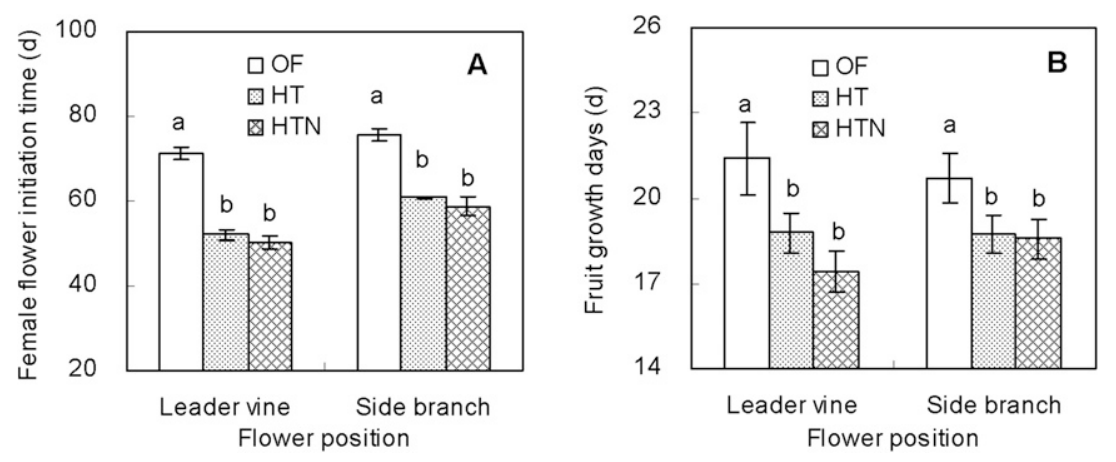

Fig. 4. (A) Initiation time of the first female flowers and (B) growth days of the first fruits in bitter melon plants under different cultivation systems. Flower initiation time was calculated as the number of days between transplanting and the appearance of the first female flower. Fruit growth days were calculated as the number of days between the appearance of the first female flower to the harvesting of its fruit. Data are means $\pm \mathrm{SE}$. Bars bearing the same letter are not significantly different at $P \leq 0.05$ according to Duncan's new multiple range test. OF $=$ open field; HT = high tunnel; HTN $=$ high tunnel with antiinsect netting.

Table 2. Morphological characteristics and biomass accumulation (not including fruits) at the end of the production period for bitter melon plants under different cultivation systems.

\begin{tabular}{lcccc}
\hline Treatment & $\begin{array}{c}\text { Leader vine } \\
\text { length }(\mathrm{m})\end{array}$ & $\begin{array}{c}\text { Leader vine } \\
\text { node (no.) }\end{array}$ & $\begin{array}{c}\text { Leader vine } \\
\text { diam }(\mathrm{mm})\end{array}$ & $\begin{array}{c}\text { Aboveground dry } \\
\text { wt }(\mathrm{g})\end{array}$ \\
\hline OF & $4.3 \pm 0.3^{\mathrm{z}} \mathrm{b}^{\mathrm{y}}$ & $75.9 \pm 1.5 \mathrm{~b}$ & $7.5 \pm 0.3 \mathrm{~b}$ & $89.2 \pm 6.3 \mathrm{~b}$ \\
HT & $8.9 \pm 0.4 \mathrm{a}$ & $112.7 \pm 2.1 \mathrm{a}$ & $9.5 \pm 0.6 \mathrm{a}$ & $182.0 \pm 29.2 \mathrm{a}$ \\
HTN & $9.0 \pm 0.1 \mathrm{a}$ & $120.2 \pm 1.6 \mathrm{a}$ & $9.9 \pm 0.2 \mathrm{a}$ & $192.7 \pm 19.7 \mathrm{a}$ \\
\hline
\end{tabular}

$\mathrm{OF}=$ open field; $\mathrm{HT}=$ high tunnel; HTN $=$ high tunnel with anti-insect netting.

${ }^{\mathrm{z}}$ Data are means $\pm \mathrm{SE}$.

${ }^{\mathrm{y}}$ The values in the same column followed by the same letter are not significantly different at $P \leq 0.05$ according to Duncan's new multiple range test.

the cumulative marketable yield in $\mathrm{OF}$ reached the upper limit of yield calculated from the formulae, but this did not occur in HT and HTN (Table 3; Fig. 5). This was supported by the observation that many immature fruits were found on the plants killed by frost in HT and HTN, but not in OF.

The percentage of scarred fruits was lower in HT and HTN than in OF, with no significant difference between HT and HTN, but the percentage of deformed fruits was not significantly different among OF, HT, and HTN (Fig. 6).

Fruit grown in HT and HTN had greater average individual weight, larger fruit size (length and diameter), thicker fruit flesh, and showed less postharvest water loss than fruit grown in OF. There were no significant differences between HTN and HT for any of the fruit quality parameters measured (Table 4). There were no significant differences among OF, HT, and HTN for fruit dry matter content and water content.

Insects and disease. There were fewer insects trapped on both blue and yellow sticky traps in HTN than in HT and OF. There were also fewer insects recorded on the blue traps, in HT vs. OF (Fig. 7A). Most of the trapped insects were found to be pests such as cucumber beetles, white flies, thrips, mites, and aphids.

For disease incidence, downy mildew, powdery mildew, gummy stem blight, and phytophthora blight were observed during the cropping period, with the latter two diseases exerting the most damage and even killing the infected plants. The percentage of disease-infected plants was lowest in HTN, followed by HT, then OF. The percentage of dead plants was lower in HT and HTN than in OF (Fig. 7B). Furthermore, disease outbreaks occurred earlier in the growing season in $\mathrm{OF}$ than in HT and HTN, but the predominant disease were gummy stem blight in OF and phytophthora blight in HT and HTN.

\section{Discussion}

HTs make organic bitter melon production possible in regions with short growing seasons. Fruit yields of $20-30 \mathrm{t} \cdot \mathrm{ha}^{-1}$ are common for OF production of bitter melon in tropical and subtropical regions (Morgan and Midmore, 2002). In the present study, under the conditions of the relatively cool and short growing season available in Ontario, a marketable yield of only $3 \mathrm{t} \cdot \mathrm{ha}^{-1}$ was achieved in OF, while yields of 29 to $36 \cdot t \cdot h^{-1}$ were achieved in HTs. The higher yields seen in HT vs. OF cultivation resulted mainly from higher average individual fruit weight, and greater numbers of marketable fruits harvested from each plant. The potential to achieve higher yields by producing larger fruit has been shown in a previous bitter melon study (Islam et al., 2014). Stronger vegetative growth, as evidenced by higher final aboveground vegetative biomass, larger vine diameter and length, and greater number of nodes (Table 5) also contributed to the higher yields in HTs (Wang, 2003). Others have also shown that the yield of bitter melon was directly related to plant growth characteristics such as vine length (Islam et al., 2014).

In addition to the higher yield, fruit harvest began 6 weeks earlier in the HTs than in the OF. The earlier fruit harvest in HTs was due to the (4-week) earlier planting dates, and higher plant growth rates in HTs compared with OF plots. The earlier planting date in the HT was made possible due to the higher spring-time soil temperature in HTs compared with OFs (Fig. 2). Soil temperature is a reliable index for determining when to plant within a HT, and cucurbit crops can be transplanted when the soil temperature at the 5 -cm depth maintains $15{ }^{\circ} \mathrm{C}$ and above (Jett, 2006). However, for spring production in OFs in Ontario, the transplanting date of warm-season crops is normally around 1 week after the average date of the latest frost. The faster plant growth in HTs may have been attributed to the higher temperature during the same period relative to transplanting date (Table 6). For bitter melons, a minimum air temperature of $18{ }^{\circ} \mathrm{C}$ is preferred during early growth (Palada and Chang, 2003). Air temperatures below $10{ }^{\circ} \mathrm{C}$ may hamper plant growth, and $20-30{ }^{\circ} \mathrm{C}$ is the optimal air temperature for fruit setting and fruit growth of bitter melon (Wang, 2003). A study in Australia has demonstrated similar effects of temperature on bitter melon plant growth (Morgan and Midmore, 2002). 

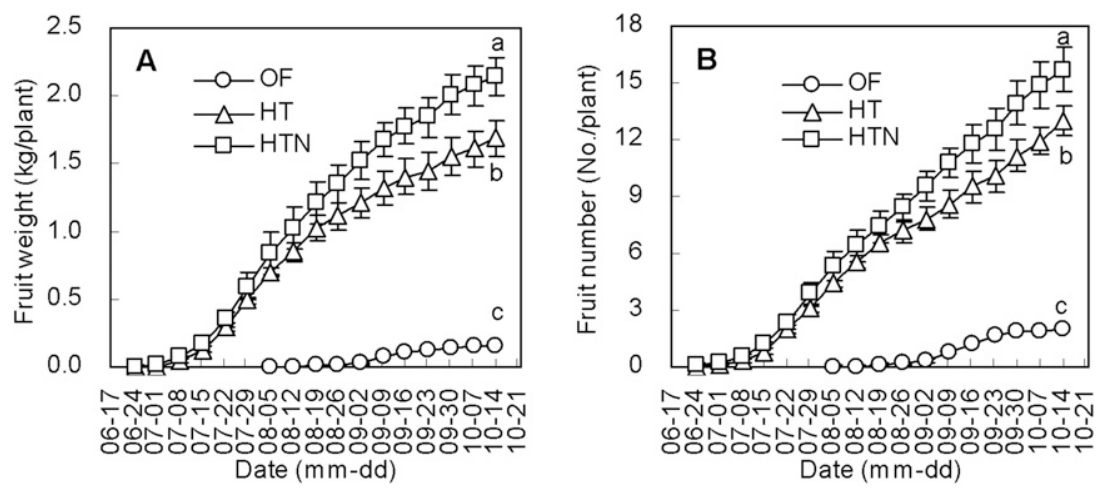

Fig. 5. (A) Weekly variation in cumulative marketable fruit weight and (B) number of harvested bitter melon fruits grown under different cultivation systems. Data are means $\pm \mathrm{SE}$. For the final cumulative yield, data marked with different letters are significantly different at $P \leq 0.05$ according to Duncan's new multiple range test. $\mathrm{OF}=$ open field; $\mathrm{HT}=$ high tunnel; HTN $=$ high tunnel with anti-insect netting.

Table 3. The fitness and estimated parameters of the formulae for the variation of cumulative marketable fruit yield of bitter melon with time in different cultivation systems. $X=$ weeks after beginning fruit harvest.

\begin{tabular}{|c|c|c|c|c|c|}
\hline Treatment & Fitted formula & $R^{2}$ & $\begin{array}{l}\text { Inflexion } \\
\text { time (wk) }\end{array}$ & $\begin{array}{c}\text { Maximum weekly } \\
\text { yield increment }\end{array}$ & $\begin{array}{l}\text { Upper limit of } \\
\text { marketable yield }\end{array}$ \\
\hline \multicolumn{6}{|c|}{ Marketable fruit weight (kg/plant) } \\
\hline $\mathrm{OF}$ & $Y=\frac{0.15}{1+e^{6.35-1.02 X}}$ & $0.994 * * *$ & 1.8 & 0.04 & $0.15\left(0.15^{z}\right)$ \\
\hline HT & $Y=1.72 e^{-7.07 e^{-0.28 X}}$ & $0.996 * * *$ & 7.0 & 0.18 & $1.72(1.69)$ \\
\hline HTN & $Y=2.28 e^{-6.53 e^{-0.26 x}}$ & $0.998 * * *$ & 7.2 & 0.22 & $2.28(2.14)$ \\
\hline \multicolumn{6}{|c|}{ Marketable fruit number (no./plant) } \\
\hline $\mathrm{OF}$ & $Y=\frac{1.97}{1+e^{6.12-0.95 X}}$ & $0.998 * * *$ & 1.9 & 0.47 & $1.97(1.97)$ \\
\hline HT & $Y=14.77 e^{-5.31 e^{-0.20 X}}$ & $0.991 * * *$ & 8.3 & 1.09 & $14.77(13.05)$ \\
\hline HTN & $Y=19.12 e^{-5.12 e^{-0.19 X}}$ & $0.996 * * *$ & 8.6 & 1.35 & $19.12(15.70)$ \\
\hline
\end{tabular}

$\mathrm{OF}=$ open field; HT = high tunnel; $\mathrm{HTN}=$ high tunnel with anti-insect netting.

${ }^{\mathrm{z}}$ Data in parentheses indicate the actual upper limit of marketable yield.

*** Calculated regression significant at $P \leq 0.001$.
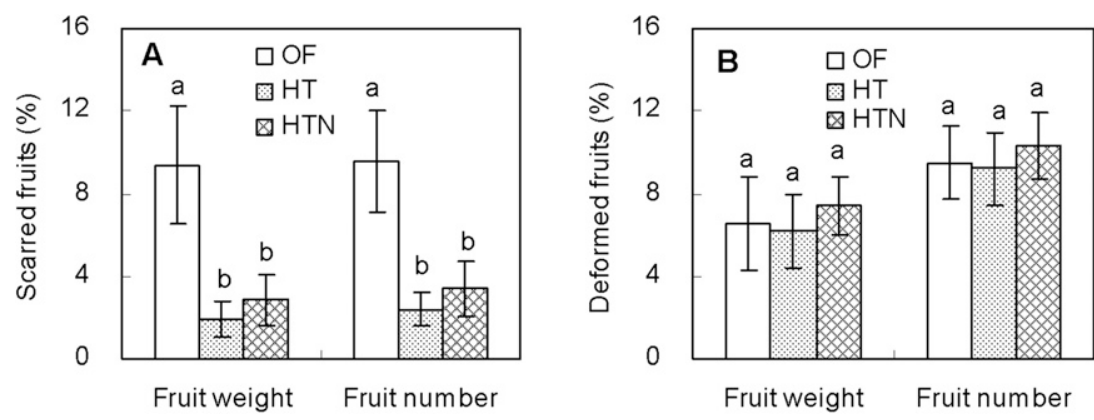

Fig. 6. (A) Percentage of scarred and (B) deformed bitter melon fruits in different cultivation systems. Data are means \pm SE. Bars bearing the same letter are not significantly different at $P \leq 0.05$ according to Duncan's new multiple range test. OF = open field; HT = high tunnel; HTN = high tunnel with antiinsect netting.

Table 4. Some quality attributes of individual fruit harvested from bitter melon plants in different cultivation systems.

\begin{tabular}{lrrr}
\hline & \multicolumn{3}{c}{ Cultivation system } \\
\cline { 2 - 4 } Parameters & \multicolumn{1}{c}{ OF } & \multicolumn{1}{c}{ HT } & HTN \\
\hline Fruit weight $(\mathrm{g})$ & $72.2 \pm 2.1^{\mathrm{z}} \mathrm{b}^{\mathrm{y}}$ & $128.9 \pm 3.1 \mathrm{a}$ & $136.8 \pm 1.5 \mathrm{a}$ \\
Fruit length (cm) & $15.2 \pm 0.0 \mathrm{~b}$ & $18.1 \pm 0.2 \mathrm{a}$ & $19.0 \pm 0.2 \mathrm{a}$ \\
Fruit diameter (mm) & $32.2 \pm 0.5 \mathrm{~b}$ & $39.0 \pm 0.1 \mathrm{a}$ & $40.3 \pm 0.4 \mathrm{a}$ \\
Flesh thickness (mm) & $8.4 \pm 0.1 \mathrm{~b}$ & $10.1 \pm 0.2 \mathrm{a}$ & $9.5 \pm 0.2 \mathrm{a}$ \\
Dry matter content (\%) & $6.6 \pm 0.1 \mathrm{a}$ & $6.9 \pm 0.3 \mathrm{a}$ & $6.9 \pm 0.2 \mathrm{a}$ \\
Water content (g.g ${ }^{-1}$ dry weight) & $14.3 \pm 0.2 \mathrm{a}$ & $13.8 \pm 0.5 \mathrm{a}$ & $13.7 \pm 0.4 \mathrm{a}$ \\
Postharvest water loss (\%) & $13.2 \pm 0.6 \mathrm{a}$ & $9.3 \pm 0.3 \mathrm{~b}$ & $10.4 \pm 0.4 \mathrm{~b}$ \\
\hline
\end{tabular}

$\mathrm{OF}=$ open field; HT $=$ high tunnel; $\mathrm{HTN}=$ high tunnel with anti-insect netting.

${ }^{\mathrm{z}}$ Data are means $\pm \mathrm{SE}$.

${ }^{\mathrm{y}}$ Values in the same row followed by the same letter are not significantly different at $P \leq 0.05$ according to

Duncan's new multiple range test.
HT production also improved fruit quality of bitter melon compared with OF production. Fruit weight, length, diameter, and flesh thickness were all greater in HTs than in OFs. The smaller fruit size in OFs is likely related to poor plant growth, since there is a strong positive relationship between fruit size and plant growth in the present study (Table 5). Also, the proportion of scarred fruits was reduced in the HTs, which may be attributed to less insect pests and lower disease incidence (Fig. 7), as well as less mechanical damage from hail and winds in the HTs. Furthermore, the rate of postharvest water loss was lower in the fruits harvested from HTs (Table 4). The cuticle is the major barrier against water loss from fruits (Riederer and Schreiber, 2001), but bitter melon fruit has a relatively thin cuticle, which makes it very susceptible to physical injury (Mohammed and Wickham, 1993) and dehydration. It is possible that the fruits in the OF plots were more commonly damaged by winds, hail, and pests, and the mechanical damage, even if visually indistinguishable, may have accelerated postharvest water loss. Another possibility is that the HTs produce a bigger fruit with a lower surface area to mass ratio which has been reported to relate positively to storage water loss in other fruits (Díaz-Pérez et al., 2007).

Overall, the results demonstrate that the organic production of bitter melon is not viable in OF cultivation in southern Ontario but it is possible in HTs. It is worthwhile noting that the OFs had higher light levels by about $20 \%$ (Fig. 2C) despite with lower temperatures, yet reduced yields, compared with the tunnels, so temperature is more limiting than light levels in OF production. In other words, the warmer microclimate inside HTs may be the most important factor contributing to the higher yield (Fig. 2A and $\mathrm{B}$; Table 6), since bitter melon is a warmseason crop, which normally grows in tropical and subtropical regions (Morgan and Midmore, 2002). It has been suggested in the cultivation of bitter melon in China that when grown within the range between 5 and $25^{\circ} \mathrm{C}$, better growth, earlier fruiting, and higher yields are attained at higher daily mean temperatures (Wang, 2003). Besides providing warmer microclimate, HTs protect the crop from winds, hail, and pests. More importantly, the tunnels also keep the aerial portions of the plants dry, thereby reducing disease incidence in many cases, since disease outbreaks often occur during prolonged periods of (leaf) tissue wetness (Palada and Chang, 2003).

While HT structures offer warmer environments and physical protection, it should be noted that HTs, by themselves, are not effective in providing adequate frost protection (Ogden and Van Iersel, 2009). This was also demonstrated in the present study, where the recent transplants in the HTs survived the frost $\left(-3{ }^{\circ} \mathrm{C}\right)$ in late May only when covered with plastic mulching film temporarily on the frost nights, but much more robust plants were completely killed by a similar frost 

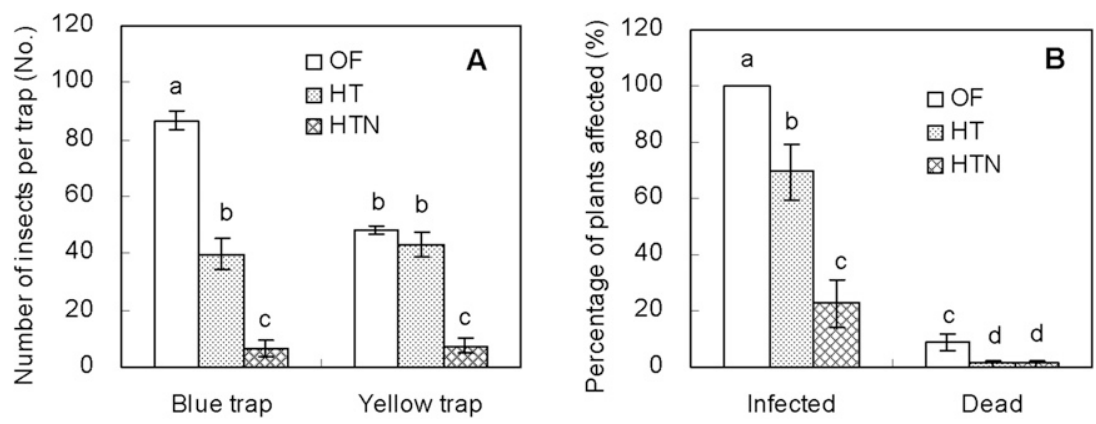

Fig. 7. (A) Numbers of trapped insects and (B) disease incidence in bitter melon plants under different cultivation systems. The insect numbers per trap in each plot are cumulative values over a 7-week collection period. Disease outbreak occurred in late June in OF, and in early October in HT and HTN. Data are means \pm SE. Bars bearing the same letter are not significantly different at $P \leq 0.05$ according to Duncan's new multiple range test. $\mathrm{OF}=$ open field; $\mathrm{HT}=$ high tunnel; HTN $=$ high tunnel with anti-insect netting.

Table 5. Correlations of plant growth attributes with marketable fruit yield (number and weight), and fruit quality traits of bitter melon.

\begin{tabular}{|c|c|c|c|c|}
\hline \multirow[b]{2}{*}{ Yield and quality attributes } & \multicolumn{4}{|c|}{ Plant growth attributes } \\
\hline & $\overline{\mathrm{ADW}}(\mathrm{g})$ & $\mathrm{LVD}(\mathrm{mm})$ & LVL (m) & LVN (no.) \\
\hline$\overline{\mathrm{MFN} \text { (no./plant) }}$ & $0.90^{\mathrm{z} * *}$ & $0.92 * *$ & $0.98 * *$ & $0.99 * *$ \\
\hline MFW (kg/plant) & $0.91 * *$ & $0.93 * *$ & $0.97 * *$ & $0.99 * *$ \\
\hline FW (g) & $0.87 * *$ & $0.92 * *$ & $0.98 * *$ & $0.99 * *$ \\
\hline $\mathrm{FL}(\mathrm{cm})$ & $0.87 * *$ & $0.92 * *$ & $0.97 * *$ & $0.99 * *$ \\
\hline $\mathrm{FD}(\mathrm{mm})$ & $0.82 *$ & $0.90 * *$ & $0.96 * *$ & $0.98 * *$ \\
\hline FT $(\mathrm{mm})$ & $0.83 *$ & $0.91 * *$ & $0.95 * *$ & $0.90 * *$ \\
\hline
\end{tabular}

$\mathrm{ADW}=$ aboveground dry weight; $\mathrm{LVD}=$ leader vine diameter; $\mathrm{LVL}=$ leader vine length; $\mathrm{LVN}=$ leader vine node; $\mathrm{MFN}=$ marketable fruit number; $\mathrm{MFW}=$ marketable fruit weight; $\mathrm{FW}=$ individual fruit weight; FL = fruit length; FD = fruit diameter; FT = flesh thickness.

${ }^{\mathrm{z}}$ Data are expressed as correlation coefficient $(r)$ values.

$*$, **Correlations significant at $P \leq 0.05$ or 0.01 , respectively.

Table 6. Cumulative growing degree days and days with daily mean temperature in the range of the referenced temperature, from transplanting until the end of production for different cultivation systems.

\begin{tabular}{|c|c|c|c|c|}
\hline \multirow[b]{2}{*}{ Treatment } & \multicolumn{2}{|c|}{ Before 8 WAT } & \multicolumn{2}{|r|}{ After 8 WAT } \\
\hline & $\overline{\mathrm{CGDD}}$ & Days above $18^{\circ} \mathrm{C}$ & $\overline{\mathrm{CGDD}}$ & Days between 20 and $30^{\circ} \mathrm{C}$ \\
\hline$\overline{\mathrm{OF}}$ & 520 & $34\left(60^{z}\right)$ & 610 & $20(25)$ \\
\hline HT & 532 & $38(66)$ & 904 & $41(39)$ \\
\hline HTN & 604 & $47(83)$ & 1036 & $54(51)$ \\
\hline
\end{tabular}

$\mathrm{OF}=$ open field; HT = high tunnel; HTN = high tunnel with anti-insect netting; CGDD = cumulative growing degree days, calculated using $10^{\circ} \mathrm{C}$ as the base temperature; WAT $=$ weeks after transplanting. ${ }_{\mathrm{z}}$ Data in parentheses are the percentage of days within the range of reference temperature.

$\left(-3{ }^{\circ} \mathrm{C}\right)$ in the middle of October when additional frost protection was not possible, due to the difficulty in covering large, climbing vines. Some measures such as rowcovers and thermal curtains have been shown to be effective for frost protection in HTs (Both et al., 2007; Lamont et al., 2003). However, rowcovers can only be used for short crops or during early stages of tall crops. Had thermal curtains been used in the HTs for fall frost protection, fruit yields may have been further increased, since the upper limit of marketable yield was not reached in HT plots (Table 3).

Anti-insect netting can benefit HT production of organic bitter melons when combined with an effective pollination strategy. Employing antiinsect netting on the HTs increased marketable yield of bitter melon fruits by $\approx 7 \mathrm{t} \cdot \mathrm{ha}^{-1}(\approx 24 \%)$ compared with no netting, without affecting fruit quality. This was primarily due to greater numbers of marketable fruits per plant in HTN than in HT, since they had similar individual fruit weights. Taking into account the similar percentage of marketable fruits between HT and HTN (Fig. 6), it is possible that the plants may have had more female flowers, or higher fruit set in HTN than in HT, due to the higher temperatures caused by anti-insect netting. As mentioned before, air temperatures of $20-30{ }^{\circ} \mathrm{C}$ are optimal for flowering and fruiting of bitter melon (Wang, 2003). In this study, the anti-insect netting increased the number of days with mean air temperature between 20 and $30{ }^{\circ} \mathrm{C}$ in HTs by $12 \mathrm{~d}$ during the period of flowering and fruiting (Table 6). Also, fruit yield of bitter melon is positively related to temperature between 5 and $25{ }^{\circ} \mathrm{C}$ (Wang, 2003) because bitter melon requires more heat than other gourds to produce maximum yield, although it can survive under lower temperatures (Morgan and Midmore, 2002).

Pest numbers in the HTs were reduced by using anti-insect netting, whose small-sized mesh excluded some insect pests from outside. Disease incidence in HTs was also reduced by anti-insect netting. In the present study, the most severe disease affecting bitter melon plants in HTs was phytophthora blight. Although the disease occurred at a similar time (around the beginning of October), it seemed to spread more rapidly in the HTs without vs. those with anti-insect netting (Fig. 7B). The physical barrier created by the nets, and the lower wind speed inside tunnels with the nets (Lubitz et al., 2016), may have reduced the dispersal of pathogen spores from outside to inside and/ or among plants inside the HTN plots (Aylor, 1990).

It is worth noting that the use of antiinsect netting for HTs may negatively affect insect pollination, and thereby reduce fruit yield from crops therein. This is particularly important in crops such as bitter melon, since it is monoecious (i.e., with male and female flowers growing separately on the same plant) and its fruit yield is highly influenced by the number of successfully pollinated female flowers (Morgan and Midmore, 2002; Palada and Chang, 2003). In the present study, to overcome this issue, hand pollination was performed daily throughout the flowering and fruiting period. This was labor intensive, and would not be feasible in large-scale commercial production. Alternatively, when using anti-insect netting, pollination for bitter melon can be achieved by introducing bees or by blowing pollen with an unloaded mister (Morgan and Midmore, 2002; Palada and Chang, 2003).

The seasonal ambient environmental conditions during this trial (from May to October) were generally representative of the typical climate in southern Ontario. From the trial results, it can be concluded that while field production of bitter melon is not feasible, it is possible to use HTs for organic production of bitter melon in southern Ontario and in regions with similar climates. The addition of anti-insect netting to HTs can further benefit bitter melon production, provided adequate consideration is given to an effective pollination strategy.

\section{Literature Cited}

Abascal, K. and E. Yarnell. 2005. Using bitter melon to treat diabetes. Altern. Complement. Ther. 11:179-184.

Aylor, D.E. 1990. The role of intermittent wind in the dispersal of fungal pathogens. Annu. Rev. Phytopathol. 28:73-92.

Behera, T.K., S. Behera, L.K. Bharathi, K.J. John, P.W. Simon, and J.E. Staub. 2010. 2 Bitter gourd: Botany, horticulture, breeding. Hort. Rev. 37:101-141.

Bethke, J.A. and T.D. Paine. 1991. Screen hole size and barriers for exclusion of insect pests of glasshouse crops. J. Entomol. Sci. 26:169-177.

Both, A.J., E. Reiss, J.F. Sudal, K.E. Holmstrom, C.A. Wyenandt, W.L. Kline, and S.A. Garrison. 2007. Evaluation of a manual energy curtain for tomato production in high tunnels. HortTechnology 17:467-472.

Canadian Food Inspection Agency. 2009. Organic products regulations. Vol. SOR/2009-176, Minister of Justice.

Carey, E.E., L. Jett, W.J. Lamont, T.T. Nennich, M.D. Orzolek, and K.A. Williams. 2009. 
Horticultural crop production in high tunnels in the United States: A snapshot. HortTechnology 19:37-43.

Díaz-Pérez, J.C., M.D. Muy-Rangel, and A.G. Mascorro. 2007. Fruit size and stage of ripeness affect postharvest water loss in bell pepper fruit (Capsicum annuum L.). J. Sci. Food Agr. 87:68-73.

Fatnassi, H., T. Boulard, C. Poncet, and M. Chave. 2006. Optimisation of greenhouse insect screening with computational fluid dynamics. Biosyst. Eng. 93:301-312.

Islam, M.S., M.A.B. Mia, M.R. Das, T. Hossain, J.U. Ahmed, and M.M. Hossain. 2014. Sex phenology of bitter gourd (Momordica charantia L.) landraces and its relation to yield potential and fruit quality. Pak. J. Agr. Sci. 51:651-658.

Jett, L.W. 2006. High tunnel melon and watermelon production. Vol. 173. University of Missouri Extension.

Lamont, W.J. 2009. Overview of the use of high tunnels worldwide. HortTechnology 19:25-29.

Lamont, W.J., M.D. Orzolek, E.J. Holcomb, K. Demchak, E. Burkhart, L. White, and B. Dye. 2003. Production system for horticultural crops grown in the Penn State high tunnel. HortTechnology 13:358-362.

Llewellyn, D., Y. Zheng, and M. Dixon. 2013. Survey of how hanging baskets influence the light environment at lower crop level in ornamental greenhouses in Ontario, Canada. HortTechnology 23:823-829.

Lubitz, W.D., Y. Zheng, Y. Kong, and D. Llewellyn. 2016. A field study of the microclimate within high tunnel greenhouses. Proc. Canadian Society for Mechanical Engineering International Congress 2016, Kelowna, British Columbia, Canada.

Ma, Q., Y. Chen, J. Qu, X. Dai, and T. Yin. 2013. Modeling and analyzing the dynamic growth for progeny in a full-sib family of Salix xuzhouenesis. J. Nanjing For. Univ. 37:13-16.

Mohammed, M. and L.D. Wickham. 1993. Extension of bitter gourd (Momordica charantia L.) storage life through the use of reduced temperature and polyethylene wraps. J. Food Qual. 16:371-382.

Morgan, W. and D. Midmore. 2002. Bitter melon in Australia. A report for the Rural Industries Research and Development Corporation. RIRDC Publication No 02/134:36. $<$ http://citeseerx.ist.psu.edu/viewdoc/download? doi $=10.31 .31 .511 .8491 \&$ rep $=$ rep8491\&type $=$ pdf $>$.

Ogden, A.B. and M.W. Van Iersel. 2009. Southern highbush blueberry production in high tunnels: Temperatures, development, yield, and fruit quality during the establishment years. HortScience 44:1850-1856.

Orzolek, M.D. 2013. Status of high tunnels in the US. Acta Hort. 987:29-32.
Palada, M.C. and L.C. Chang. 2003. Suggested cultural practices for bitter gourd, AVRDC International Cooperators' Guide. Vol. 03-547, AVRDC, pp. 5. <file://C:/Documents\%20and\% 20Settings/Administrator/My\%20Documents/ Downloads/bittergourd\%20(22).pdf $>$.

Riederer, M. and L. Schreiber. 2001. Protecting against water loss: Analysis of the barrier properties of plant cuticles. J. Expt. Bot. 52:2023-2032.

Standards Council of Canada. 2006. Organic Production Systems General Principles and Management Standards. Vol. CAN/CGSB32.310-2006. Canadian General Standards Board.

Teitel, M. 2001. The effect of insect-proof screens in roof openings on greenhouse microclimate. Agr. For. Meteorol. 110:13-25.

Wang, Q. 2003. Year-round cultivation of bitter melon with high yield. Scientific \& Technological Documentation Publishing House, Beijing, China.

Waterer, D. 2003. Yields and economics of high tunnels for production of warm-season vegetable crops. HortTechnology 13:339-343.

Zhang, F.M. 2001. Protected horticultural science. China Agricultural Publishing House, Beijing, China.

Zheng, Y. 2010. Are there sweet profits growing bitter melon. Canadian Greenhouse Conference, Toronto, Ontario, October 6-7. 